\title{
Perspectives on Endosymbiosis in Coralloid Roots: Association of Cycads and Cyanobacteria
}

\section{OPEN ACCESS}

Edited by: Kevin Garcia,

North Carolina State University,

United States

Reviewed by:

Jan de Vries,

Technische Universität Braunschweig,

Germany

Katharina Pawlowski,

Stockholm University, Sweden

${ }^{*}$ Correspondence:

Nan Li

andreali1997@126.com

Jun Duan

duanj@scib.ac.cn

Specialty section:

This article was submitted to

Microbial Symbioses,

a section of the journal

Frontiers in Microbiology

Received: 24 March 2019

Accepted: 30 July 2019

Published: 14 August 2019

Citation:

Chang ACG, Chen T, Li N and

Duan J (2019) Perspectives on Endosymbiosis in Coralloid Roots:

Association of Cycads and Cyanobacteria.

Front. Microbiol. 10:1888 doi: 10.3389/fmicb.2019.01888

\author{
Aimee Caye G. Chang 1,2,3, Tao Chen², Nan Li²* and Jun Duan ${ }^{3 *}$ \\ 1 University of Chinese Academy of Sciences, Beijing, China, ${ }^{2}$ Fairy Lake Botanical Garden, Chinese Academy of Sciences, \\ Shenzhen, China, ${ }^{3}$ South China Botanical Garden, Chinese Academy of Sciences, Guangzhou, China
}

Past endosymbiotic events allowed photosynthetic organisms to flourish and evolve in terrestrial areas. The precursor of chloroplasts was an ancient photosynthetic cyanobacterium. Presently, cyanobacteria are still capable of establishing successful symbioses in a wide range of hosts. One particular host plant among the gymnosperms is cycads (Order Cycadales) in which a special type of root system, referred to as coralloid roots, develops to house symbiotic cyanobacteria. A number of studies have explained coralloid root formation and cyanobiont invasion but the questions on mechanisms of this host-microbe association remains vague. Most researches focus on diversity of symbionts in coralloid roots but equally important is to explore the underlying mechanisms of cycads-Nostoc symbiosis as well. Besides providing an overview of relevant areas presently known about this association and citing putative genes involved in cycad-cyanobacteria symbioses, this paper aims to identify the limitations that hamper attempts to get to the root of the matter and suggests future research directions that may prove useful.

Keywords: cyanobacteria, cycads, coralloid roots, symbiosis, cyanobionts, endosymbiosis, heterocyst, hormogonia

\section{INTRODUCTION}

Cyanobacteria are the ancestors of chloroplasts. Gaining a deeper understanding on how communication between a symbiont and a host occurs at the molecular level may provide insights on the evolution of green plants. Studies addressing the function and symbiotic mechanisms between cycads and cyanobacteria in coralloid roots are scant when compared to studies of associations of cyanobionts with other host plants such as the angiosperm Gunnera, the water fern Azolla and the bryophytes Blasia and Anthoceros, to cite a few (Adams et al., 2013; Warshan, 2017). Most of the literature on cyanobacterial associations with cycads are old. Recent publications (Bergman et al., 1992; Kluge et al., 1992; Adams and Duggan, 2008; Rikkinen, 2015; Pereira, 2017) based their analyses on other host-symbiont models in an attempt to explain this ancient partnership. Therefore, this review aims to summarize current knowledge about endosymbiosis and highlighting past and present work on cycads-cyanobacterial associations. A section is also dedicated to briefly citing symbiosis-associated genes already identified from other symbiotic models that are relevant in trying to determine the core functions and mechanisms of maintaining stable symbiotic relationships. This review targets readers whose knowledge about coralloid roots of cycads are limited with the aim to spark interest in this infrequently-studied root symbiosis. This 
paper also aims to tackle the hindrances in this field of research and to suggest where future research may prove productive.

\section{Early Symbiosis}

The capacity of various microbes to interact with other life forms existed even before plants flourished - an evolutionary event triggered by symbiotic microbes (Suárez-Moo et al., 2019). Plastids originated from cyanobacteria (Douglas, 1998), also known as blue green algae, through the process of endosymbiosis which gave rise to the photosynthetic eukaryotes we now refer to as plants and algae (de Vries and Gould, 2017). Chloroplasts became an important component of plant cells because during the past endosymbiotic event by which a heterotrophic unicellular protist engulfed a free-living photosynthetic organism, the former did not allow digestion of the latter - a cyanobacterium. This is the brief story of how plastids originate (Chan and Bhattacharya, 2010). The endosymbiotic cyanobacterium became a plant organelle that harnesses solar energy and converts it to sugar and starch for food and in the process generated the oxygen in the atmosphere that is vital to most life forms (Sarma et al., 2016). In contrast to how free-living cyanobacteria evolved to become chloroplasts (de Vries and Gould, 2017), the event of symbiotic cyanobacteria that entered the roots of cycads had a different outcome. Instead of co-evolving and the symbiont being inherited intracellularly by the host from generation to generation, or giving rise to another organism, symbiotic cyanobacteria just enter and reside in cycad roots in a later part of its host's development (Norstog and Nicholls, 1997) in an engorged and dichotomously-branched root modification called coralloid roots (Ahern and Staff, 1994). Similar to this is the evolution of modified plant roots observed in pines (Faye et al., 1981) and legumes (Long, 1989) to house their respective microsymbionts for a specialized function (SuárezMoo et al., 2019). Still, regardless of how symbionts invade and evolve in their hosts, life as we know it would not have flourished if not for endosymbiosis (Govindjee and Shevela, 2011; Shestakov and Karbysheva, 2017). Research focusing on endosymbiosis is interesting, since intimate associations between two unrelated species may trigger another critical event that might cause changes in the Earth's atmospheric composition which would impact many life forms (Raven and Allen, 2003; Green, 2011; Martin et al., 2015).

Based on evidence obtained from fossils, cyanobacteria are known to be among the earliest groups of microorganisms that dominated the Earth since the late Archean to early Paleoproterozoic eon around 3500 to 2700 MYA (Krings et al., 2009; Falcon et al., 2010; Schopf, 2011; Shestakov and Karbysheva, 2017). Free-living and symbiotic cyanobacteria vary from spherical and cylindrical unicellular to filamentous multicellular forms (Narainsamy et al., 2013). Known symbiotic cyanobacteria are mostly filamentous members of the genus Nostoc (Adams and Duggan, 2008).

Cycads are the only members of gymnosperms currently capable of forming new associations with cyanobacteria. Initially reported by Reinke in 1872 (cited in Adams et al., 2013), all known species of cycads form symbiotic associations with cyanobacteria in specialized structures called coralloid roots.
Similar to cyanobionts (endosymbiotic cyanobacteria), cycads belong to the earliest members of the five major groups of seed plants - the gymnosperms Cycadales, Coniferales, Ginkgoales, Gnetales, and angiosperms. Cycads are sisters with Ginkgo (Wu et al., 2013) and both share a common ancestor with gnetophytes and conifers (Wu et al., 2007; Roodt et al., 2017). Cycads are assumed to have coexisted with dinosaurs during the Mesozoic era around 300 MYA and thus are often referred to as "living fossils" (Wu et al., 2007; Wu and Chaw, 2015; Jiang et al., 2016). Since cycads and cyanobacteria date back to ancient times, the symbiotic partnership and coevolution formed between the two may have developed millions of years ago (Usher et al., 2007). The origin of this association is still debated and questions regarding the purpose of this symbiosis and why it still prevails remains to be answered.

\section{Implications of Symbiosis Between Cycads and Cyanobacteria}

Since ancient soils 300 million years ago (Brenner et al., 2003) were not as fertile as they are today, it was thought that cycads developed a mechanism to harbor cyanobacteria to withstand poor-nutrient soils (Halliday and Pate, 1976). Specialized root structures to house endosymbiotic cyanobacteria were formed and a mutualistic association was maintained by both partners (Gutiérrez-García et al., 2019). Whether coralloid roots were formed by cycads only for the purpose of hosting cyanobionts is an open question. As opposed to cycads, terrestrial cyanobacteria can live in diverse and harsh environments (SandJensen, 2014) and are considered to be the most successful group of microorganisms on Earth (Stewart and Falconer, 2011). Free-living cyanobacteria also form associations with other life forms such as plants and fungi and in some cases with tripartite-structured cyanolichens made up of fungi, green algae and cyanobacteria (Henskens et al., 2012). As to why they need a host to spend a part of their life cycle, some scientists believe that terrestrial cyanobacteria also prefer a stable environment to survive and prevent predation and desiccation from intense heat (Adams et al., 2013). Thus, mutualistic relationships between hosts and endosymbionts are formed wherein the host provides shelter while the symbiont performs specialized functions, such as supplying the host with various needs (Walsh et al., 2011; Haselkorn, 2016). Additionally, it was suggested that cyanobacteria produce arabinogalactan-proteins (AGPs) that contribute to helping plants grow and develop (Pennell, 1992) by assisting in plant cell proliferation, expansion and differentiation (Steele-King et al., 2000). Moreover, AGPs are known to have a role in cell signaling in plant-microbe interactions (Seifert and Roberts, 2007; Jackson et al., 2012).

In a symbiotic relationship, cyanobacteria fixes nitrogen for their hosts. Naturally-occurring dinitrogen in the atmosphere is unreactive with other chemicals, thereby preventing formation of essential and useful compounds. This is where endosymbiotic cyanobacteria enter the Earth's nitrogen cycle and play a major role. Cyanobionts are able to break down the triple bonds from atmospheric dinitrogen $\left(\mathrm{N}_{2}\right)$ using the enzyme nitrogenase to convert the inert compound into useful forms of nitrogen. The 
$\mathrm{N}_{2}$ atoms can then be converted to ammonia $\left(\mathrm{NH}_{3}\right)$ (Hoffman et al., 2014), which facilitates plant growth and soil fertilization (Halliday and Pate, 1976). Other nitrifying microbes such as Nitrospira sp. assist in oxidation of ammonia to nitrite and nitrate followed by the action of denitrifying microbes that completes the nitrogen cycle (Kuypers, 2015). Nitrogen fixation in Nostoc, the dominant species symbiotic to cycads coralloid roots (Gehringer et al., 2010), occurs in structures called heterocysts, which occur as chain of cells forming a filament. Sufficient evidence shows that nitrogenase activity of cyanobacteria in symbiosis is significantly higher than in their free-living counterparts, as shown by a $25-35 \%$ increase in heterocyst formation in cyanobionts (Lindblad et al., 1985a).

Studies show that cyanobionts in symbiosis with cycads maintain complete photosynthetic apparatus - thylakoids, phycobilisomes, phycobiliproteins, and carboxysomes, associated pigments and enzyme levels comparable with free-living cyanobacteria (Lindblad et al., 1985b; Adams et al., 2013). However, as coralloid roots grow beneath the soil surface where light is insufficient or lacking, the photosystems of cyanobionts may be inactive as shown in an in vivo study conducted by Lindblad et al. (1987) where coralloid roots of Cycas revoluta showed no evidence of carbon fixation activities when compared under light and dark conditions. It was suggested that enzymes specific for efficient function of the Calvin cycle may be missing in the cyanobacteria in coralloid roots (Lindblad et al., 1987). Since cyanobionts have no sufficient light source, they are capable of heterotrophic metabolism relying on carbon solely supplied by their hosts (Lindblad, 2009). However, it is noteworthy that coralloid roots grow apogeotropically as if phototropism is occurring, and based on personal observations (Figure 1A), they oftentimes reach the soil surface exposed and thus, may become capable of receiving substantial amount of light probably through dermal breaks.

The association of cyanobacteria and cycads was also found prevalent in an incident in Guam that led to the detection of neurotoxins contained in cycad seeds. The neurotoxins cause an amyotrophic lateral sclerosis/parkinsonism-dementia complex (ALS-PDC) (Brownson et al., 2002; Meneely et al., 2016). ALSPDC is a progressive neurodegenerative disease that infected high number of Chamorro people in Guam (Metcalf et al., 2017; Zurita et al., 2019). The disease was believed to be transmitted by flying foxes that consumed cycad seeds. Flying foxes are eaten by the inhabitants of the island (Cox and Sacks, 2002; Banack and Cox, 2003). A case of "biomagnification" was said to have occurred wherein the toxin becomes more potent after being transferred from one organism to the other (Banack and Cox, 2003; Cox et al., 2003; Banack et al., 2006). But this premise remains highly debated (Snyder and Marler, 2011). In contrast, Marler et al. (2010) suggested that coralloid roots do not synthesize or biomagnify these toxins but rather, may act as toxin sinks explaining the high amounts of toxins found in the coralloid root tissues obtained from previous studies. Cyanobacteria-free cycad seedlings were in fact, found to increase in these toxins compared to symbiontinfected coralloid roots therefore refuting the role of endophytic cyanobacteria causing increase of these toxic substances in the host plant (Marler et al., 2010; Snyder and Marler, 2011). Freeliving cyanobacteria are known to produce various toxins and thus it is not surprising that symbiotic cyanobacteria synthesize toxins as well (Cox et al., 2005). This neurotoxin was claimed to be $\beta$-methylamino-L-alanine (BMAA), a non-proteinogenic amino acid produced by cyanobacteria. Even though some studies have showed that cycad host plants contain BMAA (Vega and Bell, 1967; Polsky et al., 1972; Brownson et al., 2002; Banack and Cox, 2003; Cox et al., 2003), an accurate detection method of BMAA is still being perfected until the present (Metcalf et al., 2017; Zurita et al., 2019) due to various structural isomers (Rosén and Hellenäs, 2008; Banack et al., 2010; Jiang et al., 2012) making it difficult to correctly identify the compound as BMAA. And thus, all previous claims that BMAA was detected still needed further validation.

\section{Cyanobacterial Diversity and Development in Cycads}

Cyanobionts found in cycads are predominantly species of Nostoc, but in some studies, species of Calothrix, Scytonema and Richelia were also identified (Grobbelaar et al., 1987; Costa and Lindblad, 2002; Gehringer et al., 2010). Most symbiotic cyanobacteria belong to the orders Nostocales and Stigonematales (Castenholz et al., 2001). Multiple strains of cyanobacteria can be housed in a single cycad host (Zheng et al., 2002; Thajuddin et al., 2010) and a single species of cyanobacterium can be isolated in multiple cycad hosts as well (Gehringer et al., 2010). However, in a study by Gehringer et al. (2010), only a single symbiotic Nostoc strain was found harboring the coralloid roots of the genus Macrozamia (Yamada et al., 2012). Reports indicate that other heterotrophic bacteria reside with cyanobacteria in coralloid roots (Chang et al., 1988), but only in limited populations. According to Grilli Caiola (1980), this is due to the ability of cycads to produce secondary metabolites that inhibit the growth of microorganisms, but not cyanobacteria. A concerted communication between the host and a bacterium, probably through production of certain substances, may also play a role in preventing other bacteria to overpopulate the cyanobacterial layer inside the coralloid roots (Obukowicz et al., 1981; Adams et al., 2013).

Cycads form three types of roots: (1) a primary tap root similar to the root system of most terrestrial plants, (2) lateral roots and (3) coralloid roots (Figure 1B). The latter are distinct types of roots that grow laterally and are solely in cycads that house cyanobacteria (Norstog and Nicholls, 1997; Lindblad, 2009). Prior to coralloid root formation, young, apogeotropic papillose roots called precoralloid roots are formed (Ahern and Staff, 1994). During this phase, cyanobacteria are absent and their presence is not required in initiating the development of precoralloids. At this early stage, invasion by cyanobionts happen but note that cases of uninfected precoralloids also occur (Milindasuta, 1975). This raises the question whether precoralloid roots are formed by cycads to specifically host cyanobacteria or also to serve another purpose. Nevertheless, the affinity of cyanobacteria to enter into a symbiotic relationship with 


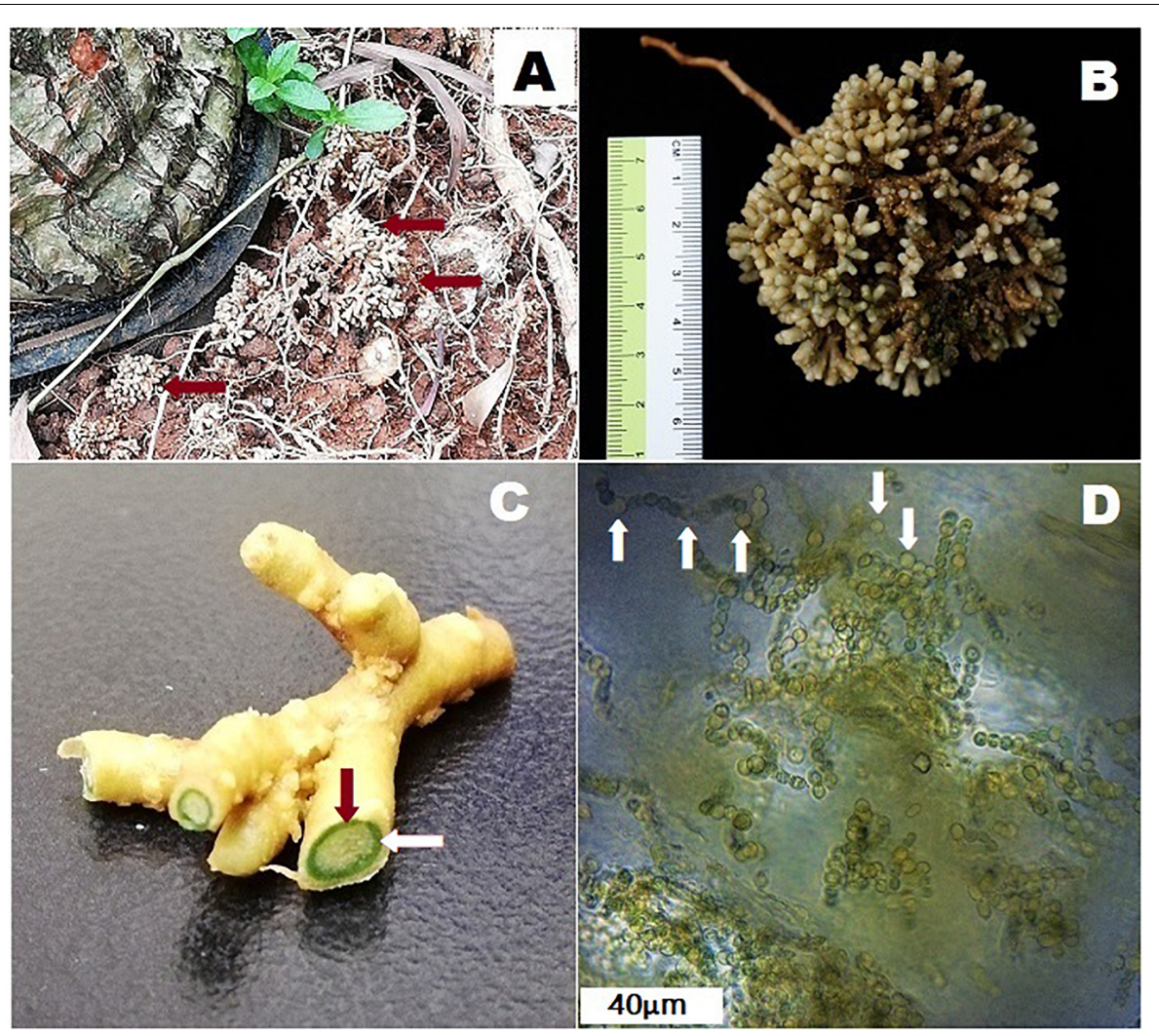

FIGURE 1 | Coralloid roots of Cycas fairylakea (A) growing apogeotropically at Shenzhen Fairy Lake Botanical Garden, (B) showing dichotomous branching of coralloid roots, $\mathbf{( C )}$ cross-section of coralloid root showing a distinct green layer - the cyanobacterial zone (the green ring pointed by the red and while arrows) and (D) microscopic image of filamentous cyanobacteria residing in the cyanobacterial zone. Heterocysts are marked with white arrows.

coralloid roots instead of with the primary and lateral roots promotes the idea that precoralloid and coralloid roots are organs developed by cycads to facilitate symbiosis. The tips of cyanobacteria-free precoralloid roots produce papillose tissue continuously (Ahern and Staff, 1994). Upon maturity, the sheath covering the papillose tissues will be replaced by a thin, external layer that generates scattered lenticels (Milindasuta, 1975; Ahern and Staff, 1994). These morphological changes, or other environmental factors, may cause disruptions in the dermal tissues of mature precoralloid roots. When cyanobacteria in the surrounding soil come in contact with the surface of coralloid roots, they gain access through the dermal breaks (Milindasuta, 1975) to eventually colonize the internal layers of the roots (Grilli Caiola and Canini, 1993; Ahern and Staff, 1994; Lindblad, 2009). At this point, the morphologically distinguishable, engorged and dichotomouslybranching coralloid roots start to form. Following initial entry, cyanobacteria migrate toward the cortex and form a distinct, circular, blue-green layer dividing the cortical layer into two (Ahern and Staff, 1994). This is called the cyanobacterial zone (Figure 1C) containing filamentous cyanobionts (Figure 1D). When coralloid roots reached this stage, the process is irreversible and a permanent symbiotic relationship between cycads and cyanobacteria has been successfully established (Grilli Caiola and Canini, 1993; Ahern and Staff, 1994; Lindblad, 2009).

\section{Associated Structures Required for Establishment of Symbiosis}

Cyanobacteria that can form associations with cycads as well as with other compatible host plants are capable of cell differentiation exhibiting various morphologies (Flores, 2012). All symbiotic cyanobacterial strains from the genus Nostoc fix nitrogen in cells called heterocysts (Adams and Duggan, 2008). At low levels of nitrogen, cyanobionts form heterocysts to facilitate nitrogen metabolism (Bergman et al., 1996). Forming heterocysts was how nitrogen fixers evolved to protect the enzyme nitrogenase from inactivation due to exposure to oxygen (Bernhard, 2010). These cells are thick-walled allowing them to block available oxygen in diffusing inside the cells making a suitable, low-oxygen microenvironment for efficient synthesis of nitrogenase for nitrogen metabolism (Tikhonovich and Provorov, 2007). Heterocysts are specialized ellipticalshaped cells produced at regularly-spaced intervals along the cyanobacterial linear cell clusters and are distinguishable due to their larger size compared to neighboring vegetative cells (Kumar et al., 2010). Cyanobionts in coralloid roots form heterocysts at higher frequency compared to free-living 
cyanobacteria but morphological changes are minimal (Adams et al., 2013). For cyanobacteria living within coralloid roots, a significant increase (up to $80 \%$ ) in heterocyst frequency was observed (Norstog and Nicholls, 1997; Adams and Duggan, 1999; Zhang et al., 2006). The increase in formation of heterocysts is said to be triggered by nitrogen starvation (Zhang et al., 2006). Therefore, an effective partnership with a plant host relies on the ability of the cyanobacteria to differentiate into heterocysts for a stable symbiosis (Meeks and Elhai, 2002).

Cyanobacteria can also form filaments called hormogonia. Hormogonium lacks heterocysts and can be morphologically distinguished from the latter as the former is capable of locomotion appearing as short motile filaments (HernándezMuñiz and Stevens, 1987). Hormogonia play a role in selfdispersal and in forming symbiotic association during the early stages of infection by responding to chemical signals produced by prospective host plants (Khayatan et al., 2017). Chemoattractants are said to be involved in stimulating hormogonia formation and directing the cyanobacteria toward the targeted plant tissue that will house the cyanobionts (Meeks et al., 2001; Meeks and Elhai, 2002; Bergman et al., 2007).

Filamentous, heterocyst-forming cyanobacteria are also capable of differentiating into spores called akinetes (KaplanLevy et al., 2010; Adams et al., 2013). When environmental conditions become unfavorable (e.g., low salinity, temperature fluctuations, lack of phosphates, low light, insufficient nutrients), active cells transform into a resting state that may last for up to 60 years in which they can be restored to their vegetative cell state when favorable conditions arise (Kaplan-Levy et al., 2010). Although not resistant to intense heat, akinetes can survive cold and desiccation (Adams and Duggan, 1999). Akinetes are rare but were reported to occur in strains of Nostoc isolated from coralloid roots (Grilli Caiola, 1980; Grobbelaar et al., 1987) and more are common in Azolla-Anabaena symbioses (Peters and Perkins, 1993). Additionally, Sukenik et al. (2007) state that resting cells can still perform minimal metabolic activities such as photosynthesis, carbon fixation and protein synthesis. Aside from akinetes, lysing or dying cells called necridia, which allow excision of cells along the filament, also occur in cyanobacteria. Characterized by thickened walls and non-granulated cells, these are commonly referred to as deteriorating cells that were unable to differentiate into heterocysts (Grilli Caiola and Pellegrini, 1979).

\section{General Mechanism of Symbiosis}

All known plant-cyanobacterial symbioses are acquired from the environment. The only exception is seen in the fern Azolla, where the cyanobiont is an integral part of the host throughout its developmental stages and gets inherited to the next generation (Bergman et al., 1996). Thus, for most symbioses, efficient communication between the host and cyanobacterium must be carried out to ensure successful entry of the symbiont (Figure 2). This requires signal molecules induced by the host and/or the symbiont during the initial stages of invasion. The general mechanism based on other host plant-cyanobacterial symbioses, as controlled by a set of regulatory genes, is that the host elicits hormogonium-inducing factors causing the surrounding cyanobacteria to transform into motile hormogonia (Adams and Duggan, 2012; Warshan, 2017). Chemotactic signals permit entry into the partner plant, subsequently demanding the host to produce hormogonium-repressing factors to allow the cyanobacteria to develop heterocysts for nitrogen fixation to occur (Warshan, 2017).

Formation of motile hormogonia is essential for successful migration of a cyanobiont to the internal tissues of its potential plant partner. Certain compounds which may be produced by the host, trigger this phenomenon and initiate cell differentiation (Khayatan et al., 2017). In plants known to accommodate symbiotic cyanobacteria, modified structures can be formed regardless of whether a cyanobiont will be present in its life cycle (Meeks and Elhai, 2002) such as the case in coralloid roots. Unlike Rhizobia, which requires specialized symbiosomes to be formed by its host, cyanobionts of coralloid roots do not need similar structures to survive within its host. However, particular spaces are dedicated to symbionts. Cyanobacteria resides in the cyanobacterial zone in the roots of cycads, in the red stem glands of Gunnera, in dorsal leaf cavities of Azolla water fern, in slime cavities within the thallus of hornworts, in auricles underneath the thallus of liverworts, and in the bladders of the fungi Geosiphon pyriformis (Adams et al., 2013). Among these plant-cyanobacterial symbioses, it is only in Gunnera where the cyanobiont invasion occurs intracellularly (Meeks and Elhai, 2002; Adams et al., 2013). In the coralloid roots, an acidic viscous mucilage in the cortex (Grilli Caiola, 1980), also observed by the authors, is present in the cortex layer probably involved in attracting motile hormogonia filaments as this was the case observed in Gunnera (Nilsson et al., 2006). Mucilage-filled cavities were also observed in hornworts and liverworts and this heat-labile putative signal inducer is yet to be characterized, but was estimated to be a low molecular mass protein around $12 \mathrm{kDa}$ (Adams et al., 2013). In line with this, root extracts from cycad coralloid roots were found to significantly initiate hormogonia formation in strains of Nostoc (Campbell and Meeks, 1989; Bergman et al., 1996; Meeks, 1998) suggesting hosts produce hormogonia-inducing factors (Nilsson et al., 2006). In an in vitro study, hormogoniainducing factor (HIF) was not released in a culture medium with excess nitrogen. Thus, HIF production is assumed to be stimulated when nitrogen levels are depleted (Campbell and Meeks, 1989; Adams et al., 2013). Aside from the HIF signal, plant hosts are believed to release various chemoattractants to entice potential symbionts. These were hypothesized to be sugar-based molecules, since simple sugars were proven to be attractants for hormogonia initiation (Nilsson et al., 2006; Adams et al., 2013). Recently, a bioassay was conducted using crude methanolic extracts of Cycas revoluta coralloid roots that transformed symbiotic Nostoc filaments into motile hormogonia. This led to the successful isolation of a hormogonium-inducing factor from cycads characterized as diacylglycerol 1-palmitoyl-2linoleoyl-sn-glycerol (Hashidoko et al., 2019).

Once a cyanobiont successfully enters its host, the plant partner must stop releasing hormogonia-inducing factors to halt hormogonia formation. The reason is to direct the cyanobiont to the next stage of symbiosis and to start forming heterocysts 


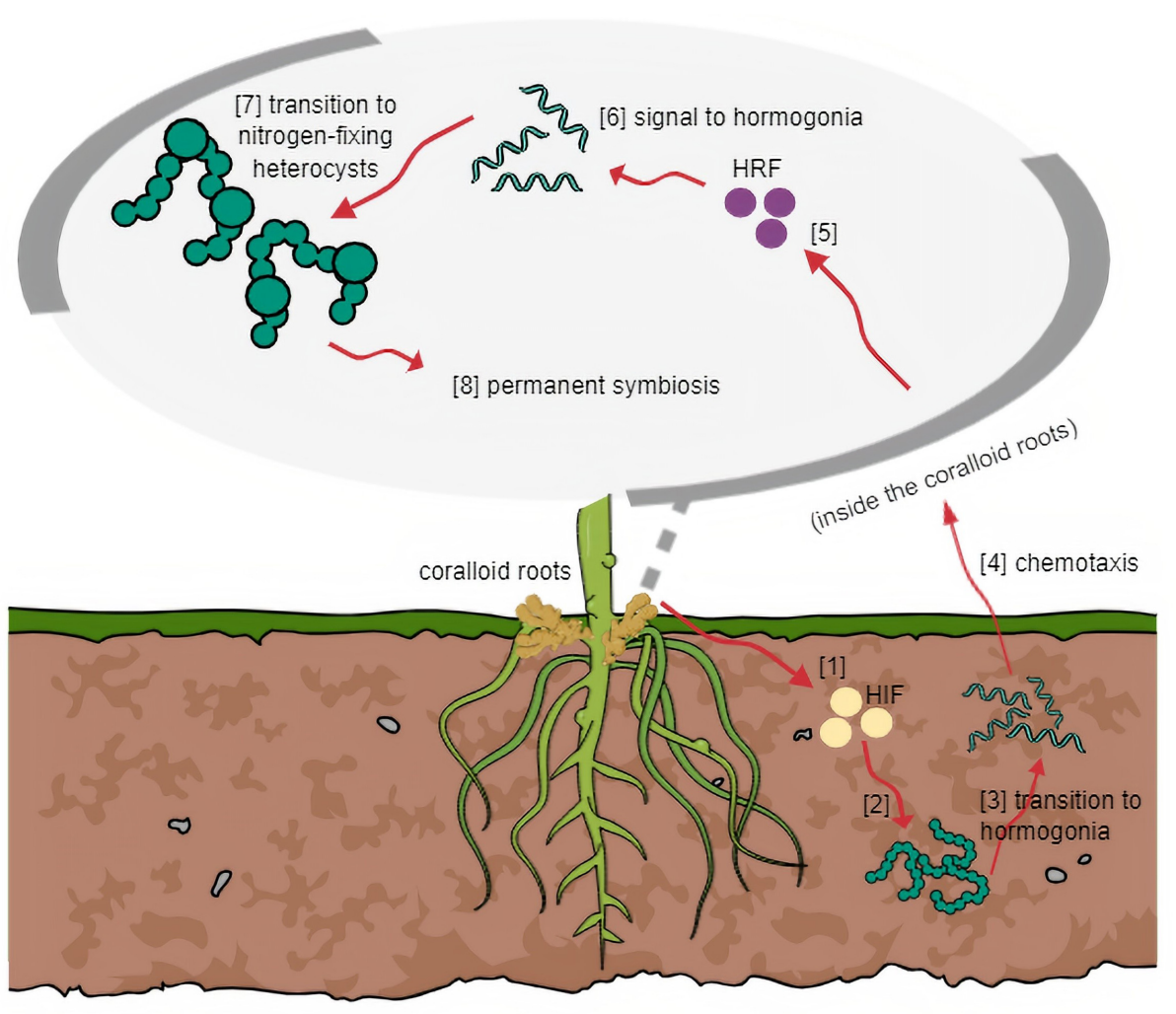

FIGURE 2 | General mechanism of symbiosis based on other host plant-cyanobiont models. (1) HIF is released by host and (2) triggers cyanobacteria in surrounding soil to (3) transition into motile filaments. (4) Through chemotaxis, host attracts hormogonia following cyanobacterial entry. (5) Host releases HRF and (6) signals hormogonia that entered the host successfully to (7) transition into heterocysts-forming cells. (8) Symbiosis at this stage becomes irreversible.

for nitrogen fixation to occur - a task that cannot be performed by hormogonia filaments. Therefore, the release of hormogoniarepressing factors (HRF) hinders HIF activities. Cohen and Meeks (1997) observed this phenomenon using aqueous tissue extracts of Anthoceros wherein activation of two genes blocks hormogonium formation and the expressions are only induced by HRF but not HIF.

Besides inducing and repressing factors, high amounts of phenolic substances are also present in the mucilaginous material embedded in the cyanobacterial zone of coralloid roots and surrounding cortical layers (Lobakova et al., 2004). Phenolic substances are rich sources of antimicrobial compounds and secondary metabolites (Obukowicz et al., 1981). Interestingly, phenolics are also known to participate in cell signaling and might play a role in establishing and maintaining stable cycad-cyanobacterial symbioses (Grilli Caiola, 1980; Obukowicz et al., 1981).

\section{An Overview of Genes Involved in Cycads-Cyanobacteria Symbiosis}

Though still limited, sequencing of representative complete genomes of hosts and cyanobionts led to the identification of genes involved in plant host-cyanobacterial symbiosis (Ran et al., 2010; Li et al., 2018). This section aims to list some studied genes and their functions significant in the establishment of symbiosis as well as other genes they interact with (Table 1). Although most of the genes cited here were not studied using cycad coralloid roots, a similar, if not exact, genetic mechanism in cycad-cyanobacterial symbiosis seems to be occurring as the genes discussed in this section were commonly found among plant-cyanobacterial symbioses.

As mentioned previously, HRF are involved in halting hormogonium formation after initial migration of the symbiont into its target organ in the host that varies among plant hosts as mentioned in the previous section. Using Anthoceros tissue extracts, $\mathrm{hrmU}$ and $\mathrm{hrmA}$ genes were discovered that suppresses hormogonia formation and allow differentiation of cells into heterocysts (Cohen and Meeks, 1997). The expression of these two genes appears to be controlled by the host, which hinders further activities attempted by HIF (Cohen and Meeks, 1997; Meeks et al., 1999). Other open reading frames (ORFs) - hrmI, hrmR, hrmK and hrmE - were identified that were similar to a family coding for transcriptional inhibitor proteins (Campbell et al., 2003). It was proposed that external repressing signals can possibly be detected by Nostoc incapacitating Hrm proteins in successfully binding to hrm operons and this affects transcription of genes that induce hormogonium formation (Meeks et al., 1999; Campbell et al., 2003; Adams et al., 2013).

The ability to form heterocysts is a vital feature for a cyanobiont to establish symbiosis with a host. Without 
TABLE 1 | Symbiosis-related genes from host-symbiont models cited in this manuscript.

\begin{tabular}{|c|c|c|}
\hline GENES & ORGANISMS/s & GENERAL FUNCTION/S \\
\hline hrm & Nostoc-Anthoceros & Suppresses hormogonia formation allowing cell differentiation into heterocysts \\
\hline het & Nostoc-Anthoceros & Responsible for heterocyst formation \\
\hline ntc & Nostoc-Anthoceros & Regulates nitrogen and has a role in activation of other symbiotic genes \\
\hline hep & Anabaena-Azolla & Induces formation of thickened cell envelope in heterocyst cells \\
\hline nif & Nostoc-Anthoceros, Anabaena-Azolla & Involves in formation of nitrogenase complexes \\
\hline sig & Nostoc-Anthoceros & Plays a role in signaling to promote symbiont entry to host tissue \\
\hline ctp & Nostoc-Anthoceros, Synechocystis-Anthoceros & Involves in photosynthetic activities \\
\hline tpr & Nostoc-Anthoceros & Regulates cell cycle and functions in protein transport mechanisms \\
\hline
\end{tabular}

heterocysts, a cyanobiont cannot fix nitrogen for its host. Mutations in het $R$ and hetF $\operatorname{did}$ not allow one strain of Nostoc to differentiate into heterocysts and thus, those genes were determined to be directly responsible for heterocyst formation (Wong and Meeks, 2001). The main activator for the development of heterocysts is the hetR gene, which works simultaneously with het $F$ gene coding, which gives rise to a protein that enhances subsequent transcription of hetR (Wolk, 2000; Wong and Meeks, 2002; Zhang et al., 2006). The expression of $n t c A$ gene is necessary for the production of proteins that cyanobacteria use to regulate nitrogen and in addition, is involved in activating the transcription of various genes, including the hetR gene (Herrero et al., 2001). Studies showed that a mutant species of Nostoc with a defective ntcA gene failed to infect its host despite retention of hormogonia-forming capacity and therefore might be linked with the activation of other genes required for a successful symbiotic relationship to be established (Vega-Palas et al., 1992; Herrero et al., 2001; Adams et al., 2013). A study by Leganes et al. (1994) in Anabaena showed that an altered hepA gene disrupts proper formation of the cell envelope in both heterocysts and akinetes. The thickened walls, made up of a polysaccharide layer, are essential for nitrogen fixation activities to be concentrated in the heterocyst cells and prevent oxygen diffusion (Tikhonovich and Provorov, 2007). As a consequence of a non-functional hepA gene, normal development of the cell envelope is impossible and affects the ability of the cyanobiont to fix nitrogen in its host (Leganes et al., 1994). Both free-living and symbiotic bacteria have nif genes not restricted to cyanobacteria (Corbin et al., 1982; Fay, 1992). Those genes are responsible for forming nitrogenase complexes that convert unusable atmospheric dinitrogen to useful forms like ammonia and in this process, the nifD and nifK genes encode a dinitrogenase heterotetramer that contains an active site to reduce dinitrogen atoms (Dos Santos et al., 2012). The nifDK genes work together with it redox partner, an iron protein encoded by nifH gene, to complete the structure and function of nitrogenase complex (Jasniewski et al., 2018). Therefore, these genes are important for maintaining mutual associations with a host because defects in the genes may affect the nitrogen-fixing capacity of the symbiont (Spaink, 1998).

Several genes have been identified, but their significance in symbioses is still poorly understood. A sigma factor gene, sigH, which appears to be directed by HIF, might play a role in the ability of symbionts to increase invasion success in a targeted host (Campbell et al., 1998). Likewise, the ctpH gene, which is in close proximity with the sigH gene, is also controlled by HIF in Nostoc (Adams et al., 2013) and has a function in the photosystem II mechanisms in Synechocystis (Anbudurai et al., 1994). This gene is interesting as it may have varying physiological roles in different symbiotic strains. Another gene, $\operatorname{tp} r N$, codes for proteins known to be necessary in various functions, such as regulating the cell cycle, suppressing transcription mechanisms and transporting proteins (Lamb et al., 1995). This gene is also essential for heterocyst maturation process (Campbell et al., 1996). In line with this, Meeks et al. (1999) observed that a silenced tprN gene in $N$. punctiforme caused no phenotypic change but the infection rate doubled compared to the wild-type strain, and its transcription elevated when exposed to both HIF and HRF exudates of $A$. punctatus. However, the implications and its involvement in the infection process are still unknown.

\section{LIMITATIONS IN CYCAD-CYANOBACTERIA RESEARCH}

A substantial number of studies have focused on the growth and development of coralloid roots and the diversity of the endosymbiont community within the cyanobacterial zone using cultures and 16S identification methods (Costa et al., 1999; Thajuddin et al., 2010; Yamada et al., 2012). The underlying mechanisms, however, have been left unexplored. Probable reasons challenging the study of symbiosis compared to other hosts with a cyanobacterial partner are discussed in this section.

One of the difficulties in this field of research is studying the in vivo development of cycad - cyanobacterial symbiosis. To determine the mutualistic interactions exhibited by both partners, a significant length of time, which may take years of research, might be needed to confirm and validate hypotheses as development in cycads takes much time. Tissue culture methods are also lacking for most cycads to facilitate in vitro experimental assays that could be used to compare wild-type and symbiont-free conditions. Another reason is the availability of coralloid roots of good quantity and quality. According to McLuckie (1922) cited in Milindasuta (1975) and also based on personal observations, even when coralloid roots are present, a green layer in the cortex may be absent (Nilsson et al., 2006). Moreover, the availability of both root tissue samples and cyanobionts per plant host are often insufficient for experiments, especially when replicates are 
needed. Thus, samples are usually pooled using a number of representative hosts. Also, most studies obtain their samples from botanic gardens and not from the wild. Although promising results can still be achieved, gathering samples from natural habitats could add more interesting findings.

Another frustration in this field of research is trying to separate root tissues from the endosymbiont as well as the endosymbiont from the sticky mucilaginous material. Various methods have been proposed (Ferris and Hirsch, 1991; Lindblad et al., 1991; Gehringer et al., 2010), but completely separating them from each requires improvement as most requires manually scraping off the green symbiont from the roots. In determining the functions of cycads and their cyanobionts during symbiosis, the gene expression must be analyzed capturing the symbiotic condition while both partners are together. This eliminates the need to separate them because it would cause changes in gene expression, but poses the more difficult task of how to monitor their association in vivo.

\section{CONCLUSION AND FUTURE PERSPECTIVES}

Research on coralloid roots is not new, but progress has been quite slow compared to research on Rhizobia and other host-cyanobiont associations. Due to the limitations mentioned above, the research field has been confined to studying the diversity of symbionts obtained from various cycad hosts and revalidating previous hypotheses on how both partners benefit from each other. Cruz-Morales et al. (2017) identified novel biosynthetic gene clusters unique to cycad coralloid rootscyanobacteria symbiosis through genome mining, a research area worth undertaking to understand coevolution and to discover pathways responsible for the synthesis of natural products. With the advancements in genomic research that are becoming more affordable, even for small-scale laboratories, studying cycad host-cyanobiont symbiosis may now move forward at a quicker pace. First, whole genome and transcriptomic sequencing proved to be a valuable source of information regarding genetic functions and evolution (Ran et al., 2010; Li et al., 2018; Eily et al., 2019). In line with this, DNA microarray technology can now be used for analysis of expressed genes of microbes from multiple genomes simultaneously using probes to determine up or downregulated genes. Alternatively, RNA sequencing (RNA-Seq) of cyanobiont genomes approximately 5.4-9.0 Mbp - in obligate cyanobiont Nostoc azollae and facultative cyanobiont Nostoc punctiforme PCC 73102 of Azolla filiculoides, respectively (Ran et al., 2010) and 6.7 Mbp in Nostoc cycadae of Cycas revoluta (Kanesaki et al., 2018) - can be

\section{REFERENCES}

Adams, D. G., Bergman, B., Nierzwicki-Bauer, S. A., Duggan, P. S., Rai, A. N., and Schubler, A. (2013). "Cyanobacterial-plant symbioses," in The Prokaryotes Prokaryotic Biology and Symbiotic Associations, eds E. Rosenberg, E. F. DeLong, S. Lory, E. Stackebrandt, and F. Thompson (Berlin: Springer-Verlag), 359-400. doi: 10.1007/978-3-642-30194-0_17 utilized that could detect new genes and splicing events. Aside from ruling out the need for manual separation of microbe from host tissues, Next generation sequencing (NGS) technology provides high resolution data. Likewise, tissue-specific whole transcriptome profiling might be applied to coralloid root tissues with genome size of about 20-30 Gbp (Wang et al., 2018) for determining expressed genes during symbiosis. Furthermore, gaining bioinformatics skills is necessary to maximize the analysis of the outputs obtained from huge amounts of genomic data.

Cyanobacteria are also valuable sources of metabolites (Haque et al., 2017). Thus, venturing into cycad and/or cyanobiont metabolomics research might help to identify useful products, such biofertilizers, antimicrobials and other natural products of economic importance. It may also facilitate studies on cyanotoxins and biomagnification theories. Likewise, metabolites are also believed to play major roles in cell signaling and communication and could also assist in providing insights on symbiotic pathways and identification of enzymes involved in symbiosis. Many areas of cycad-cyanobacteria symbiosis are still waiting to be explored. With technology rapidly advancing simultaneously with the skills of researchers, restrictions previously deemed overwhelming currently appear to be promising.

\section{AUTHOR CONTRIBUTIONS}

TC and AC designed the study. AC gathered the materials and wrote the manuscript. TC, NL, and JD reviewed the manuscript. All authors read and approved the final manuscript.

\section{FUNDING}

This work was supported by the special financial project from the National Forestry and Grassland Administration for Rescues and Breeding of Wild Rare and Endangered Species (NL 2017, 2018, and 2019), the Shenzhen Urban Management Bureau (NL 201411), the Shenzhen Key Laboratory of Southern Subtropical Plant Diversity, Fairy Lake Botanical Garden (TC 2017-2019), and South China Botanical Garden (JD 2017-2019), Chinese Academy of Sciences.

\section{ACKNOWLEDGMENTS}

We would like to thank Dr. David E. Boufford at Harvard University Herbaria for the help while preparing the manuscript.

Adams, D. G., and Duggan, P. (1999). Heterocyst and akinete differentiation in cyanobacteria: Tansley Review No. 107. New Phytol. 144, 3-33. doi: 10.1046/j. 1469-8137.1999.00505.x

Adams, D. G., and Duggan, P. (2008). Cyanobacteria-bryophyte symbioses. J. Exp. Bot. 59, 1047-1058. doi: 10.1093/jxb/ern005

Adams, D. G., and Duggan, P. S. (2012). "Signalling in cyanobacteria-plant symbioses," in Signaling and Communication in Plant Symbiosis, eds S. Perotto 
and F. Baluška (Berlin: Springer Berlin Heidelberg), 93-121. doi: 10.1007/9783-642-20966-6_5

Ahern, C. P., and Staff, I. A. (1994). Symbiosis in cycads: the origin and development of coralloid roots in Macrozamia communis (Cycadeceae). Am. J. Bot. 81, 1559-1570. doi: 10.1002/j.1537-2197.1994.tb11467.x

Anbudurai, P. R., Mor, T. S., Ohad, I., Shestakov, S. V., and Pakrasi, H. B. (1994). The ctpA gene encodes for the C-terminal processing protease for the D1 protein of the photosystem II reaction center complex. Proc. Natl. Acad. Sci. U.S.A. 91, 8082-8086. doi: 10.1073/pnas.91.17.8082

Banack, S. A., and Cox, P. A. (2003). Biomagnification of cycad neurotoxins in flying foxes: implications for ALS-PDC in Guam. Neurology 61, 387-389. doi: 10.1212/01.wnl.0000078320.18564.9f

Banack, S. A., Downing, T. G., Spacil, Z., Purdie, E. L., Metcalf, J. S., Downing, S., et al. (2010). Distinguishing the cyanobacterial neurotoxin $\beta$-N-methylaminoL-alanine (BMAA) from its structural isomer 2,4-diaminobutyric acid (2,4DAB). Toxicon 56, 868-879. doi: 10.1016/j.toxicon.2010.06.006

Banack, S. A., Murch, S. J., and Cox, P. A. (2006). Neurotoxic flying foxes as dietary items for the Chamorro people, Marianas Islands. J. Ethnopharmacol. 106, 97-104. doi: 10.1016/j.jep.2005.12.032

Bergman, B., Johansson, C., and Soderback, E. (1992). The Nostoc-Gunnera symbiosis. New Phytol. 122, 379-400. doi: 10.1111/j.1469-8137.1992.tb00067.x

Bergman, B., Matveyev, A., and Rasmussen, U. (1996). Chemical signaling in cyanobacterial-plant symbioses. Trends Plant Sci. 1, 191-197. doi: 10.1016/ 1360-1385(96)10021-2

Bergman, B., Rai, A. N., and Rasmussen, U. (2007). "Cyanobacterial assocations," in Associative and Endophytic Nitrogen-Fixing Bacteria and Cyanobacterial Associations, eds C. Elmerich and W. E. Newton (Dordrecht: Springer), 257-301.

Bernhard, A. (2010). The nitrogen cycle: processes, players, and human impact. Nat. Educ. Knowl. 3:25.

Brenner, E. D., Stevenson, D. W., and Twigg, R. W. (2003). Cycads: evolutionary innovations and the role of plant-derived neurotoxins. Trends Plant Sci. 8, 446-452. doi: 10.1016/s1360-1385(03)00190-0

Brownson, D. M., Mabry, T. J., and Leslie, S. W. (2002). The cycad neurotoxic amino acid, beta-N-methylamino-L-alanine (BMAA), elevates intracellular calcium levels in dissociated rat brain cells. J. Ethnopharmacol. 82, 159-167. doi: 10.1016/s0378-8741(02)00170-8

Campbell, E. L., Brahamsha, B., and Meeks, J. C. (1998). Mutation of an alternative sigma factor in the cyanobacterium Nostoc punctiforme results in increased infection of its symbiotic plant partner, Anthoceros punctatus. J. Bacteriol. 180, 4938-4941.

Campbell, E. L., Hagen, K. D., Cohen, M. F., Summers, M. L., and Meeks, J. C. (1996). The $\operatorname{devR}$ gene product is characteristic of receivers of twocomponent regulatory systems and is essential for heterocyst development in the filamentous cyanobacterium Nostoc sp. strain ATCC 29133. J. Bacteriol. 178, 2037-2043. doi: 10.1128/jb.178.7.2037-2043.1996

Campbell, E. L., and Meeks, J. C. (1989). Characteristics of hormogonia formation by symbiotic Nostoc spp. in response to the presence of Anthoceros punctatus or its extracellular products. Appl. Environ. Microbiol. 55, 125-131.

Campbell, E. L., Wong, F. C. Y., and Meeks, J. C. (2003). DNA binding properties of the HrmR protein of Nostoc punctiforme responsible for transcriptional regulation of genes involved in the differentiation of hormogonia. Mol. Microbiol. 47, 573-582. doi: 10.1046/j.1365-2958.2003.03320.x

Castenholz, R. W., Wilmotte, A., Herdman, M., Rippka, R., Waterbury, J. B., Iteman, I., et al. (2001). "Phylum BX. Cyanobacteria," in Bergey's Manual of Systematic Bacteriology, eds D. R. Boone, R. W. Castenholz, and G. M. Garrity (New York, NY: Springer), 473-599. doi: 10.1007/978-0-387-21609-6_27 Chan, C. X., and Bhattacharya, D. (2010). The origin of plastids. Nat. Educ. 3:84.

Chang, D. C. N., Grobelaar, N., and Coetzee, J. (1988). SEM observations on cyanobacteria-infected cycad coralloid roots. S. Afr. J. Bot. 54, 491-495. doi: 10.1016/s0254-6299(16)31284-4

Cohen, M. F., and Meeks, J. C. (1997). A hormogonium regulating locus, hrmUA, of the cyanobacterium Nostoc punctiforme strain ATCC 29133 and its response to an extract of a symbiotic plant partner Anthoceros punctatus. Mol. Plant Microbe Interact. 10, 280-289. doi: 10.1094/mpmi.1997.10.2.280

Corbin, D., Ditta, G., and Helinski, D. R. (1982). Clustering of nitrogen fixation (nif genes) in Rhizobium meliloti. J. Bacteriol. 149, 221-228.
Costa, J. L., and Lindblad, P. (2002). "Cyanobacteria in symbiosis with cycads," in Cyanobacteria in Symbiosis, eds A. N. Rai, B. Bergman, and U. Rasmussen (Dordrecht: Kluwer), 195-205. doi: 10.1007/0-306-48005-0_11

Costa, J. L., Paulsrud, P., and Lindblad, P. (1999). Cyanobiont diversity within coralloid roots of selected cycad species. FEMS Microbiol. Ecol. 28, 85-91. doi: 10.1016/s0168-6496(98)00095-6

Cox, P. A., Banack, S. A., and Murch, S. J. (2003). Biomagnification of cyanibacterial neurotoxins and neurodegenerative disease among the Chamorro people of Guam. Proc. Natl. Acad. Sci. U.S.A. 100, 13380-13383. doi: 10.1073/pnas.2235808100

Cox, P. A., Banack, S. A., Murch, S. J., Rasmussen, U., Tien, G., Bidigare, R. R., et al. (2005). Diverse taxa of cyanobacteria produce $\beta$-N-methylamino-Lalanine, a neurotoxic amino acid. Proc. Natl. Acad. Sci. U.S.A. 102, 5074-5078. doi: 10.1073/pnas.0501526102

Cox, P. A., and Sacks, O. W. (2002). Cycad neurotoxins, consumption of flying foxes, and ALS-PDC disease in Guam. Neurology 58, 956-959. doi: 10.1212/ wnl.58.6.956

Cruz-Morales, P., Corona-Gomez, A., Selem-Mojica, N., Perez-Farrera, M. A., Barona-Gomez, F., and Cibrian-Jaramillo, A. (2017). The cycad coralloid root contains a diverse endophytic bacterial community with novel biosynthetic gene clusters unique to its microbiome. bioRxiv 1-53.

de Vries, J., and Gould, S. B. (2017). The monoplastidic bottleneck in algae and plant evolution. J. Cell Sci. 0, 1-13. doi: 10.1242/jcs.203414

Dos Santos, P. C., Fang, Z., Mason, S. W., Setubal, J. C., and Dixon, R. (2012). Distribution of nitrogen fixation and nitrogenase-like sequences amongst microbial genomes. BMC Genomics 13:162. doi: 10.1186/1471-2164-13-162

Douglas, S. E. (1998). Plastid evolution: origins, diversity and trends. Curr. Opin. Genet. Dev. 8, 655-661. doi: 10.1016/s0959-437x(98)80033-6

Eily, A. N., Pryer, K. M., and Li, F.-W. (2019). A first glimpse at genes important to the azolla-nostoc symbiosis. Symbiosis 78, 149-162. doi: 10.1007/s13199-01900599-2

Falcon, L. I., Magallon, S., and Castillo, A. (2010). Dating the cyanobacterial ancestor of the chloroplast. Int. Soc. Microb. Ecol. 4, 777-783. doi: 10.1038/ ismej.2010.2

Fay, P. (1992). Oxygen relations in nitrogen fixation in cyanobacteria. Microbiol. Rev. 56, 340-373.

Faye, M., Rancillac, M., and David, A. (1981). Determinism of the mycorrhizogenic root formation in Pinus pinaster Sol. New Phytol. 87, 557-565. doi: 10.1111/j. 1469-8137.1981.tb03226.x

Ferris, M. J., and Hirsch, C. F. (1991). Method for isolation and purification of cyanobacteria. Appl. Environ. Microbiol. 57, 1448-1452.

Flores, E. (2012). Restricted cellular differentiation in cyanobacterial filaments. Proc. Natl. Acad. Sci. U.S.A. 109, 15080-15081. doi: 10.1073/pnas.1213507109

Gehringer, M. M., Pengelly, J. J. L., Cuddy, W. S., Fieker, C., Forster, P. I, and Neilan, B. A. (2010). Host selection of symbiotic cyanobacteria in 31 species of the Australian cycad genus: Macrozamia (Zamiaceae). Mol. Plant Microbe Interact. 23, 811-822. doi: 10.1094/MPMI-23-6-0811

Govindjee, and Shevela, D. (2011). Adventures with cyanobacteria: a personal perspective. Front. Plant Sci. 2:28. doi: 10.3389/fpls.2011.00028

Green, B. R. (2011). Chloroplast genomes of photosynthetic eukaryotes. Plant J. 66, 34-44. doi: 10.1111/j.1365-313x.2011.04541.x

Grilli Caiola, M. (1980). On the phycobionts of the cycad coralloid roots. New Phytol. 85, 537-544. doi: 10.1111/j.1469-8137.1980.tb00769.x

Grilli Caiola, M., and Canini, A. (1993). Structure and physiology of Cycad coralloid roots. G. Bot. Ital. 127, 428-445. doi: 10.1111/j.1574-6941.2012. 01403.x

Grilli Caiola, M., and Pellegrini, S. (1979). Effects of various nitrogen sources on Nostoc punctiforme (Kützing). Caryologia 32, 485-498. doi: 10.1080/00087114. 1979.10796812

Grobbelaar, N., Scott, W. E., Hattingh, W., and Marshall, J. (1987). The identification of the coralloid root endophytes of the southern African cycads and the ability of the isolates to fix dinitrogen. S. Afr. J. Bot. 53, 111-118. doi: 10.1016/s0254-6299(16)31444-2

Gutiérrez-García, K., Bustos-Díaz, E. D., Corona-Gómez, J. A., Ramos-Aboites, H. E., Sélem-Mojica, N., Cruz-Morales, P., et al. (2019). Cycad coralloid roots contain bacterial communities including cyanobacteria and Caulobacter spp. that encode niche-specific biosynthetic gene clusters. Genome Biol. Evol. 11, 319-334. doi: 10.1093/gbe/evy266 
Halliday, J., and Pate, J. (1976). Symbiotic nitrogen fixation by coralloid roots of the Cycad Macrozamia riedlei: physiological characteristics and ecological significance. Aust. J. Plant Physiol. 3, 349-358.

Haque, F., Banayan, S., Yee, J., and Chiang, Y. W. (2017). Extraction and applications of cyanotoxins and other cyanobacterial secondary metabolites. Chemosphere 183, 164-175. doi: 10.1016/j.chemosphere.2017. 05.106

Haselkorn, R. (2016). Cyanobacteria. Curr. Biol. 19, 277-278.

Hashidoko, Y., Nishizuka, H., Tanaka, M., Murata, K., Murai, Y., and Hashimoto, M. (2019). Isolation and characterization of 1-palmitoyl-2-linoleoyl-snglycerol as a hormogonium-inducing factor (HIF) from the coralloid roots of Cycas revoluta (Cycadaceae). Sci. Rep. 9:4751. doi: 10.1038/s41598-01939647-8

Henskens, F. L., Green, T. G., and Wilkins, A. (2012). Cyanolichens can have both cyanobacteria and green algae in a common layer as a major contributors to photosynthesis. Ann. Bot. 110, 555-563. doi: 10.1093/aob/mcs108

Hernández-Muñiz, W., and Stevens, S. E. (1987). Characterization of the motile hormogonia of Mastigocladus laminosus. J. Bacteriol. 169, 218-223. doi: 10. 1128/jb.169.1.218-223.1987

Herrero, A., Muro-Pastor, A. M., and Flores, E. (2001). Nitrogen control in cyanobacteria. J. Bacteriol. 183, 411-425. doi: 10.1128/jb.183.2.411-425.2001

Hoffman, B. M., Lukoyanov, D., Yang, Z. Y., Dean, D. R., and Seefeldt, L. C. (2014). Mechanism of nitrogen fixation by nitrogenase: the next stage. Chem. Rev. 114, 4041-4062. doi: 10.1021/cr400641x

Jackson, O., Taylor, O., Adams, D. G., and Knox, J. P. (2012). Arabinogalactan proteins occur in the free-living cyanobacterium genus Nostoc and in plantNostoc symbioses. MPMI 25, 1338-1349. doi: 10.1094/MPMI-04-12-0095-R

Jasniewski, A. J., Sickerman, N. S., Hu, Y., and Ribbe, M. W. (2018). The fe protein: an unsung hero of nitrogenase. Inorganics 6:25. doi: 10.3390/ inorganics6010025

Jiang, G. F., Hinsinger, D. D., and Strijk, J. S. (2016). Comparison of intraspecific, interspecific and intergeneric chloroplast diversity in Cycads. Sci. Rep. 6:31473. doi: $10.1038 /$ srep31473

Jiang, L., Aigret, B., De Borggraeve, W. M., Spacil, Z., and Ilag, L. L. (2012). Selective LC-MS/MS method for the identification of BMAA from its isomers in biological samples. Anal. Bioanal. Chem. 403, 1719-1730. doi: 10.1007/s00216012-5966-y

Kanesaki, Y., Hirose, M., Hirose, Y., Fujisawa, T., Nakamura, Y., Watanabe, S., et al. (2018). Draft genome sequence of the nitrogen-fixing and hormogoniainducing cyanobacterium Nostoc cycadae strain WK-1, isolated from the coralloid roots of Cycas revoluta. Genome Announc. 6:e00021-18. doi: 10.1128/ genomeA.00021-18

Kaplan-Levy, R. N., Hadas, O., Summers, M. L., Rücker, J., and Sukenik, A. (2010). "Akinetes: dormant cells of Cyanobacteria," in Dormancy and Resistance in Harsh Environments. Topics in Current Genetics, eds E. Lubzens, J. Cerda, and M. Clark (Berlin: Springer), 5-27. doi: 10.1007/978-3-642-12422-8_2

Khayatan, B., Bains, D. K., Cheng, M. H., Cho, Y. W., Hyunh, J., Kim, R., et al. (2017). A putative $\mathrm{O}$-linked $\beta-\mathrm{N}$-acetylglucosamine transferase is essential for hormogonium development and motility in the filamentous cyanobacterium Nostoc punctiforme. J. Bacteriol. 199:e00075-17.

Kluge, M., Mollenhauer, D., Mollenhauer, R., and Kape, R. (1992). Geosiphon pyriforme, an endosymbiotic consortium of a fungus and a cyanobacterium (Nostoc), fixes nitrogen. Bot. Acta 105, 343-344. doi: 10.1111/j.1438-8677.1992. tb00309.x

Krings, M., Hass, H., Kerp, H., Taylor, T. N., Agerer, R., and Dotzler, N. (2009). Endophytic cyanobacteria in a 400-million-yr-old land plant: a scenario for the origin of a symbiosis? Rev. Palaeobot. Palynol. 153, 62-69. doi: 10.1016/j. revpalbo.2008.06.006

Kumar, K., Mella-Herrera, R. A., and Golden, J. W. (2010). Cyanobacterial heterocysts. Cold Spring Harb. Perspect. Biol. 2:a000315. doi: 10.1101/ cshperspect.a000315

Kuypers, M. M. (2015). Microbiology: a division of labour combined. Nature 528, 487-488. doi: 10.1038/528487a

Lamb, J. R., Tugendreich, S., and Hieter, P. (1995). Tetratrico peptide repeat interaction: to TPR or not to TPR? Trends Biochem. Sci. 20, 257-259. doi: 10.1016/s0968-0004(00)89037-4

Leganes, F., Fernandez-Piñas, F., and Wolk, C. P. (1994). Two mutations that block heterocyst differentiation have different effects on akinete differentiation in Nostoc ellipsosporum. Mol. Microbiol. 12, 679-684. doi: 10.1111/j.1365-2958. 1994.tb01055.x

Li, F. W., Brouwer, P., Carretero-Paulet, L., Cheng, S., de Vries, J., Delaux, P. M., et al. (2018). Fern genomes elucidate land plant evolution and cyanobacterial symbioses. Nat. Plants 4, 460-472. doi: 10.1038/s41477-018-0188-8

Lindblad, P. (2009). Cyanobacteria in symbiosis with cycads. Microbiol. Monogr. 8, 225-233. doi: 10.1007/7171_2008_118

Lindblad, P., Atkins, C. A., and Pate, J. S. (1991). N2-Fixation by freshly isolated Nostoc from coralloid roots of the cycad Macrozamia riedlei (Fisch. ex Gaud.) Gardn. Plant Physiol. 95, 753-759. doi: 10.1104/pp.95.3.753

Lindblad, P., Hallblom, L., and Bergman, B. (1985b). The cyanobacterium-Zamia symbiosis: $\mathrm{C} 2 \mathrm{H} 2$ reduction and heterocyst frequency. Symbiosis 1, 19-28.

Lindblad, P., Bergman, B., Hofsten, A. V., Hallblom, L., and Nylund, J. E. (1985a). The cyanobacterium-Zamia symbiosis: an ultrastructural study. New Phytol. 101, 707-716. doi: 10.1111/j.1469-8137.1985.tb02876.x

Lindblad, P., Rai, A. N., and Bergman, B. (1987). The Cycas revoluta-Nostoc symbiosis: enzyme activities of nitrogen and carbon metabolism in the cyanobiont. J. Gen. Microbiol. 133, 1695-1699. doi: 10.1099/00221287-133-71695

Lobakova, E. S., Dubravina, G. A., and Zagoskina, N. V. (2004). Formation of phenolic compounds in apogeotrophic roots of cycad plants. Russ. J. Plant Physiol. 51, 486-493. doi: 10.1023/b:rupp.0000035741.31754.e6

Long, S. R. (1989). Rhizobium-legume nodulation: life together in the underground. Cell 56, 203-214. doi: 10.1016/0092-8674(89)90893-3

Marler, T. E., Snyder, L. R., and Shaw, C. A. (2010). Cycas micronesia (Cycadales) plants devoid of endophytic cyanobacteria increase in beta-methylamino-Lalanine. Toxicon 56, 563-568. doi: 10.1016/j.toxicon.2010.05.015

Martin, W. F., Garg, S., and Zimorski, V. (2015). Endosymbiotic theories for eukaryote origin. Philos. Trans. R. Soc. B 370:20140330. doi: 10.1098/rstb.2014. 0330

McLuckie, J. (1922). Studies in symbiosis II The apogeotropic roots of macrozamia spiralis and their physiological significance. Proc. Linn. Soc. N.S.W. 47, 319-328.

Meeks, J. C. (1998). Symbiosis between nitrogen-fixing cyanobacteria and plants. Bioscience 48, 266-276. doi: 10.2307/1313353

Meeks, J. C., Campbell, E., Hagen, K., Hanson, T., Hitzeman, N., and Wong, F. (1999). "Developmental alternatives of symbiotic Nostoc punctiforme in response to its symbiotic partner Anthoceros punctatus," in The Phototrophic Prokaryotes, eds G. A. Peschek, W. Loffelhardt, and G. Schmetterer (New York, NY: Kluwer/Plenum), 665-678. doi: 10.1007/978-1-4615-4827-0_77

Meeks, J. C., and Elhai, J. (2002). Regulation of cellular differentiation in filamentous cyanobacteria in free-living and plant-associated symbiotic growth states. Microbiol. Mol. Biol. Rev. 66, 94-121. doi: 10.1128/mmbr.66.1.94-121. 2002

Meeks, J. C., Elhai, J., Thiel, T., Potts, M., Larimer, F., Lamerdin, J., et al. (2001). An overview of the genome of Nostoc punctiforme, a multicellular, symbiotic cyanobacterium. Photosynth. Res. 70, 85-106.

Meneely, J. P., Chevallier, O. P., Graham, S., Greer, B., Green, B. D., and Elliott, C. T. (2016). $\beta$-methylamino-L-alanine (BMAA) is not found in the brains of patients with confirmed Alzheimer's disease. Sci. Rep. 6:36363. doi: 10.1038/srep 36363

Metcalf, J. S., Lobner, D., Banack, S. A., Cox, G. A., Nunn, P. B., Wyatt, P. B., et al. (2017). Analysis of BMAA enantiomers in cycads, cyanobacteria, and mammals: in vivo formation and toxicity of d-BMAA. Amino Acids 49, 14271439. doi: $10.1007 / \mathrm{s} 00726-017-2445-y$

Milindasuta, B. E. (1975). Developmental anatomy of coralloid roots in cycads. Am. J. Bot. 62, 468-472. doi: 10.1002/j.1537-2197.1975.tb14071.x

Narainsamy, K., Marteyn, B., Sakr, S., Cassier-Chauvat, C., and Chauvat, F. (2013). Genomics of the pleiotropic glutathione system in cyanobacteria (Chapter 5). Adv. Bot. Res. 65, 157-188. doi: 10.1016/b978-0-12-394313-2.00005-6

Nilsson, M., Rasmussen, U., and Bergman, B. (2006). Cyanobacterial chemotaxis to extracts of host and nonhost plants. FEMS Microbiol. Ecol. 55, 382-390. doi: 10.1111/j.1574-6941.2005.00043.x

Norstog, K. J., and Nicholls, T. J. (1997). The Biology of the Cycads. Ithaca, NY: Cornell University Press.

Obukowicz, M., Schallerm, M., and Kennedy, G. S. (1981). Ultrastructure and phenolic histochemistry of the Cycas revoluta-Anabaena symbiosis. New Phytol. 87, 751-759. doi: 10.1111/j.1469-8137.1981.tb01711.x 
Pennell, R. I. (1992). “Cell surface arabinogalactan proteins, arabinogalactans and plant development," in Perspectives in Plant Cell Recognition, eds J. A. Collow and J. R. Green (Cambridge: Cambridge University Press), 105-121.

Pereira, A. L. (2017). The Unique Symbiotic System Between a Fern and a Cyanobacterium, Azolla-Anabaena azollae: Their potential as biofertilizer, feed, and remediation. London: IntechOpen.

Peters, G. A., and Perkins, S. K. (1993). The Azolla-Anabaena symbiosis: endophyte continuity in the Azolla life cycle is facilitated by epidermal trichomes I: partitioning of endophytic Anabaena into developing sporocarps. New Phytol. 123, 53-64. doi: 10.1111/j.1469-8137.1993.tb04531.x

Polsky, F. I., Nunn, P. B., and Bell, E. A. (1972). Distribution and toxicity of $\alpha$-amino- $\beta$-methylaminopropionic acid. Fed. Proc. 31, 1473-1475.

Ran, L., Larsson, J., Vigil-Stenman, T., Nylander, J. A. A., Ininbergs, K., Zheng, W. W., et al. (2010). Genome erosion in a nitrogen-fixing vertically transmitted endosymbiotic multicellular cyanobacterium. PLoS One 5:e11486. doi: 10.1371/ journal.pone.0011486

Raven, J. A., and Allen, J. F. (2003). Genomics and chloroplast evolution: what did cyanobacteria do for plants? Genome Biol. 4:209.

Rikkinen, J. (2015). Cyanolichens. Biodivers. Conserv. 24, 973-993. doi: 10.1007/ s10531-015-0906-8

Roodt, D., Lohaus, R., Sterck, L., Swanepoel, R. L., Van de Peer, Y., and Mizrachi, E. (2017). Evidence for an ancient whole genome duplication in the cycad lineage. PLoS One 12:e0184454. doi: 10.1371/journal.pone.0184454

Rosén, J., and Hellenäs, K. E. (2008). Determination of the neurotoxin BMAA (beta-N-methylamino-L-alanine) in cycad seed and cyanobacteria by LCMS/MS (liquid chromatography tandem mass spectrometry). Analyst 133, 1785-1789. doi: 10.1039/b809231a

Sand-Jensen, K. (2014). Ecophysiology of gelatinous Nostoc colonies: unprecedented slow growth and survival in resource-poor and harsh environments. Ann. Bot. 114, 17-33. doi: 10.1093/aob/mcu085

Sarma, M. K., Kaushik, S., and Goswami, P. (2016). Cyanobacteria: a metabolic power house for harvesting solar energy to produce bio-electricity and biofuels. Biomass Bioenergy 90, 187-201. doi: 10.1016/j.biombioe.2016.03.043

Schopf, J. W. (2011). "The fossil record: tracing the roots of the cyanobacterial lineage," in The Ecology of Cyanobacteria, eds B. A. Whitton and M. Potts (Dordrecht: Kluwer Academic Publishers), 13-35. doi: 10.1007/0-306-468 55-7_2

Seifert, G. J., and Roberts, K. (2007). The biology of arabinogalactan proteins. Annu. Rev. Plant Biol. 58, 137-161.

Shestakov, S. V., and Karbysheva, E. A. (2017). The origin and evolution of cyanobacteria. Biol. Bull. Rev. 7, 259-272. doi: 10.1134/s207908641704 0090

Snyder, L. R., and Marler, T. E. (2011). Rethinking cycad metabolite research. Commun. Integr. Biol. 4, 86-88. doi: 10.4161/cib.4.1.14084

Spaink, H. P. (1998). The Rhizobiaceae: Molecular Biology of Model PlantAssociated Bacteria. Berlin: Springer.

Steele-King, C. G., Willats, W. G. T., and Paul Knox, J. (2000). “Arabinogalactanproteins and cell development in roots and somatic embryos," in Cell and Developmental Biology of Arabinogalactan-Proteins, eds E. A. Nothnagel, A. Bacic, and A. E. Clarkecpesnm (Boston, MA: Springer).

Stewart, I., and Falconer, I. R. (2011). "Cyanobacteria and cyanobacterial toxins," in Oceans and Human Health: Risks and Remedies from the Seas, eds P. J. Walsh, S. Smith, L. Fleming, H. Solo-Gabriele, and W. H. Gerwick (Cambridge, MA: Academic Press), 271-296.

Suárez-Moo, P. D. J., Vovides, A. P., Griffith, M. P., Barona-Gómez, F., and Cibrián-Jaramillo, A. (2019). Unlocking a high bacterial diversity in the coralloid root microbiome from the cycad genus Dioon. PLoS One 14:e0211271. doi: 10.1371/journal.pone.0211271

Sukenik, A., Beardall, J., and Hadas, O. (2007). Photosynthetic characterization of developing and mature akinetes of Aphanizomenon ovalisporum (Cyanoprokaryota). J. Phycol. 43, 780-788. doi: 10.1111/j.1529-8817.2007. 00374.x

Thajuddin, N., Muralitharan, G., Sundaramoorthy, M., Ramamoorthy, R., Ramachandran, S., Akbarsha, M. A., et al. (2010). Morphological and genetic diversity of symbiotic cyanobacteria from cycads. J. Basic Microbiol. 50, 254-265. doi: 10.1002/jobm.200900343

Tikhonovich, I. A., and Provorov, N. A. (2007). "Beneficial plant-microbe interactions," in Studies in Plant Science: Comprehensive and Molecular
Phytopathology, eds Y. T. Dyakov, T. Korpela, and V. G. Dzhavakhiya (Amsterdam: Elsevier), 365-420. doi: 10.1016/b978-044452132-3/50018-3

Usher, K. M., Bergman, B., and Raven, J. A. (2007). Exploring cyanobacterial mutualisms. Annu. Rev. Ecol. Evol. Syst. 38, 255-273. doi: 10.1146/annurev. ecolsys.38.091206.095641

Vega, A., and Bell, E. A. (1967). $\alpha$-amino- $\beta$-methylaminopropionic acid, a new amino acid from seeds of Cycas circinalis. Phytochemistry 6, 759-762. doi: 10.1016/s0031-9422(00)86018-5

Vega-Palas, M. A., Flores, E., and Herrero, A. (1992). NtcA, a global nitrogen regulator from the cyanobacterium Synechococcus that belongs to the Crp family of bacterial regulators. Mol. Microbiol. 6, 1853-1859. doi: 10.1111/j. 1365-2958.1992.tb01357.x

Walsh, P. J., Smith, S., Fleming, L., Solo-Gabriele, H., and Gerwick, W. H. (2011). Cyanobacteria and Cyanobacterial Toxins. Oceans and Human Health: Risks and Remedies from the Seas. Cambridge, MA: Academic Press, 271-296.

Wang, Y., Li, N., Chen, T., and Gong, Y. (2018). Generation and characterization of expressed sequence tags (ESTs) from coralloid root cDNA library of Cycas debaoensis. Plant Divers. 40, 245-252. doi: 10.1016/j.pld.2018.09.002

Warshan, D. (2017). Cyanobacteria in Symbiosis with Boreal Forest Feathermosses: From Genome Evolution and Gene Regulation to Impact on the Ecosystem. $\mathrm{PhD}$ Dissertation, Stockholm University: Stockholm.

Wolk, C. P. (2000). "Heterocyst formation in Anabaena," in Prokaryotic Development, eds Y. V. Brun and L. J. Shimkets (Washington, DC: ASM Press), 83-104. doi: 10.1128/9781555818166.ch4

Wong, F. C. Y., and Meeks, J. C. (2002). Establishment of functional symbiosis between the cyanobacterium Nostoc punctiforme and the bryophyte Anthoceros punctatus requires genes involved in nitrogen control and initiation of heterocyst differentiation. Microbiology 148, 315-323. doi: 10.1099/00221287148-1-315

Wong, F. C. Y., and Meeks, J. C. (2001). The hetF gene product is essential to heterocyst differentiation and affects HetR function in the cyanobacterium Nostoc punctiforme. J. Bacteriol. 183, 2654-2661. doi: 10.1128/JB.183.8.26542661.2001

Wu, C. S., and Chaw, S. M. (2015). Evolutionary stasis in cycad plastomes and the first case of plastome GC-biased gene conversion. Genome Biol. Evol. 7, 2000-2009. doi: 10.1093/gbe/evv125

Wu, C. S., Chaw, S. M., and Huang, Y. Y. (2013). Chloroplast phylogenomics indicates that Ginkgo biloba is sister to cycads. Genome Biol. Evol. 5, 243-254. doi: 10.1093/gbe/evt001

Wu, C. S., Wang, Y. N., Liu, S. M., and Chaw, S. M. (2007). Chloroplast genome (cpDNA) of Cycas taitungensis and $56 \mathrm{cp}$ protein-coding genes of Gnetum parvifolium: insights into cpDNA evolution and phylogeny of extant seed plants. Mol. Biol. Evol. 24, 1366-1379. doi: 10.1093/molbev/msm059

Yamada, S., Ohkubo, S., Miyashita, H., and Setoguchi, H. (2012). Genetic diversity of symbiotic cyanobacteria in Cycas revoluta (Cycadaceae). FEMS Microbiol. Ecol. 81, 696-706. doi: 10.1111/j.1574-6941.2012.01403.x

Zhang, C. C., Laurent, S., Sakr, S., Peng, L., and Bedu, S. (2006). Heterocyst differentiation and pattern formation in cyanobacteria: a chorus of signals. Mol. Microbiol. 59, 367-375. doi: 10.1111/j.1365-2958.2005.04979.x

Zheng, W., Song, T., Bao, X., Bergman, B., and Rasmussen, U. (2002). High cyanobacterial diversity in coralloid roots of cycads revealed by PCR fingerprinting. FEMS Microbiol. Ecol. 40, 215-222. doi: 10.1111/j.1574-6941. 2002.tb00954.x

Zurita, J., Zguna, N., Andrys, R., Strzelczak, A., Jiang, L., Thorsen, G., et al. (2019). Chiral analysis of b-methylamino alanine (BMAA) enantiomers after (+)-1(9-fluorenyl)-ethyl chloroformate (FLEC) derivatization and LC-MS/MS. Anal. Methods 11, 432-442. doi: 10.1039/c8ay02287a

Conflict of Interest Statement: The authors declare that the research was conducted in the absence of any commercial or financial relationships that could be construed as a potential conflict of interest.

Copyright (c) 2019 Chang, Chen, Li and Duan. This is an open-access article distributed under the terms of the Creative Commons Attribution License (CC BY). The use, distribution or reproduction in other forums is permitted, provided the original author(s) and the copyright owner(s) are credited and that the original publication in this journal is cited, in accordance with accepted academic practice. No use, distribution or reproduction is permitted which does not comply with these terms. 